\title{
Massive obscure overt gastrointestinal bleeding secondary to an ileal carcinoid diagnosed and treated using double-balloon enteroscopy
}

A 49-year-old woman was transferred to our hospital because of hematochezia, which had lasted for 24 hours. Her past medical history was positive for osteogenesis imperfecta type 4 and asthma. On clinical examination, the patient was pale and tachycardic with a resting pulse rate of 110 . Her blood pressure was 80/40. Hemoglobin was $4.4 \mathrm{mmol} / \mathrm{L}$ (reference values $7.4-10.0$ ) and hematocrit 0.21 $(0.35-0.47)$. The remaining laboratory parameters were within the reference range.

The patient was transfused with six units of packed red blood cells and underwent an esophagogastroduodenoscopy (EGD) which was normal. Ileocolonoscopy revealed a very long and tortuous colon, and blood emanating from the terminal ileum valve. The patient then underwent an oral double-balloon enteroscopy (DBE), which disclosed a bleeding lesion $400 \mathrm{~cm}$ distal to the pylorus ( Fig. 1). The bleeding was stopped using argon plasma coagulation (APC; Erbe, Tübingen, Germany) ( Fig. 2). After achieving hemostasis, we injected $0.5 \mathrm{ml}$ India ink into the submucosa, $4 \mathrm{~cm}$ proximal to the tumor. The patient had no further episodes of bleeding and remained stable during her hospitalization.

After 2 weeks, the patient underwent an elective laparotomy. During the operation the marked segment was easily identified, there was no retraction of the mesentery, and a 7-cm-long segment of ileum was resected. Histopathology revealed a $1.2-\mathrm{cm}-$ diameter neuroendocrine tumor (NET) ( $\bullet$ Fig. 3). The resection margins were free. Computed tomography (CT) of the abdomen revealed multiple metastases. The patient was placed on a long-lasting somatostatin analog (Sandostatin) and remained clinically stable.

Despite their low incidence, NETs are the second most frequent tumors of the small intestine $[1,2]$. The most common symptoms of gastrointestinal NET are nonspecific and include abdominal pain, bloating, and diarrhea [1,2]. Gastrointestinal bleeding is very rare, usually resulting from ulceration of the mucosa [2]. Laboratory diagnosis is established by demonstration of elevated plasma chromo-

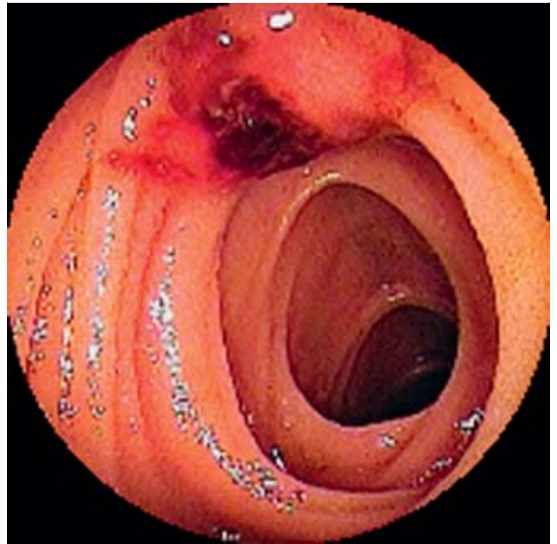

Fig. 1 Bleeding neuroendocrine tumor localized in the ileum, $400 \mathrm{~cm}$ distal to the pylorus. The lesion was raised with an ulcerated center with active bleeding.

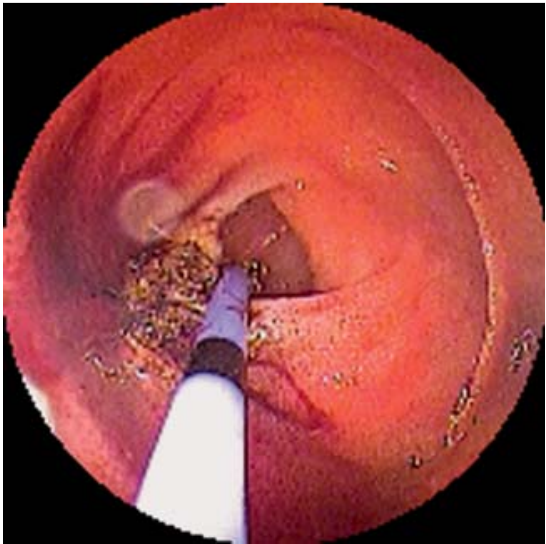

Fig. 2 Application of pulsed argon plasma coagulation $(30 \mathrm{~W})$ via a thin probe. A total of five applications each lasting 5 seconds were necessary to stop the bleeding.

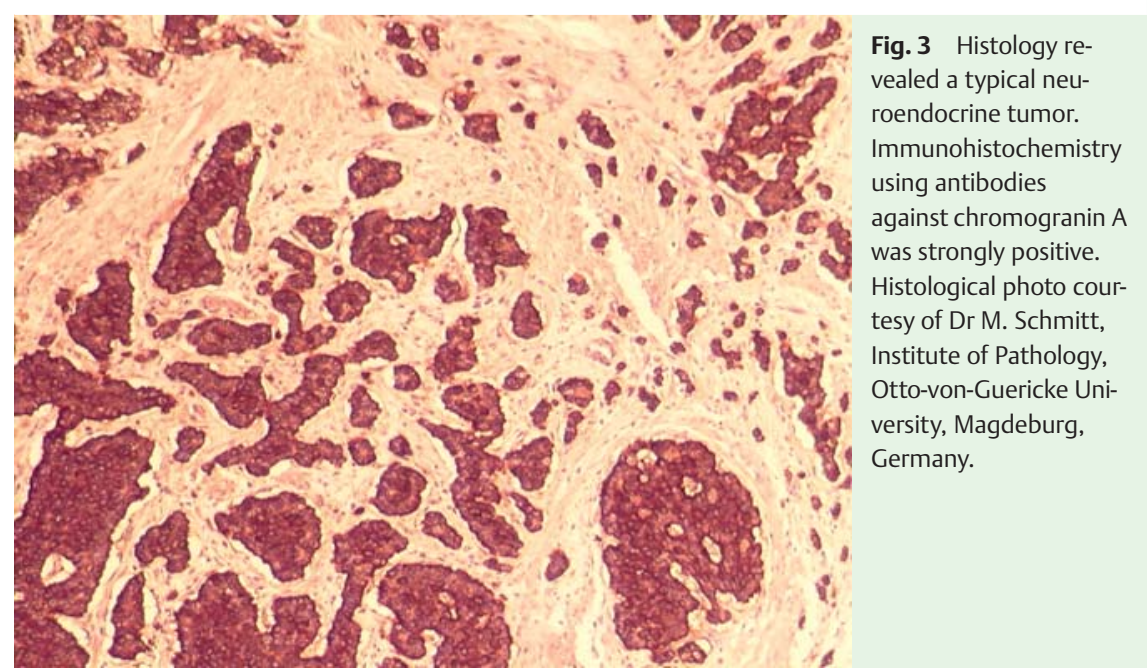

granin A or urinary 5-hydroxyindoleacetic acid levels, while localization is accomplished by octreotide scintigraphy or CT scan [1]. Recently, capsule endoscopy has been reported as a useful method to localize small-bowel NET [2,3]. Because of the ability to investigate the small bowel, DBE is another potential method to search for NETs.

Our case is interesting for several reasons. First, we show that small-bowel NET should be kept as a differential diagnosis of midgut bleeding. Second, we demonstrate that an ileal NET can be diagnosed by performing an oral DBE. Third, endoscopic therapy using APC was successful to stop the bleeding from the ulcerated carcinoid. And finally, DBE was also a useful method to mark the site of this small tumor by using India ink. We conclude that DBE may be a potential method to investigate the presence of small-bowel $\mathrm{NET}$, to treat a bleeding lesion, and to help the surgeon localize the lesion intraoperatively by having marked the site during endoscopy.

Endoscopy_UCTN_Code_CCL_1AC_2AC

Competing interests: None 
K. Mönkemüller ${ }^{1,2}$, L. C. Fry ${ }^{1,2}$, R. Kuhn ${ }^{3}$, S. Rickes ${ }^{4}$

1 Division of Gastroenterology, Hepatology and Infectious Diseases, Otto-von-Guericke University, Magdeburg, Germany

2 Department of Internal Medicine, Gastroenterology and Infectious Diseases, Marienhospital Bottrop, Bottrop, Germany

3 Department of Surgery, Universitätsklinikum Magdeburg, Otto-von-Guericke University, Magdeburg, Germany

4 St Salvator Krankenhaus, Halberstadt, Germany

\section{References}

1 Modlin IM, Kidd M, Latich I et al. Current status of gastrointestinal carcinoids. Gastroenterology 2005; 128: 1717-1751

2 Forner A, Mata A, Puig M et al. Ileal carcinoid tumor as a cause of massive lower-GI bleeding: the role of capsule endoscopy. Gastrointest Endosc 2004; 60: 483-485

3 van Tuyl SA, van Noorden JT, Timmer $R$ et al. Detection of small-bowel neuroendocrine tumors by video capsule endoscopy. Gastrointest Endosc 2006; 64: 66-72

\section{Bibliography}

DOI $10.1055 / \mathrm{s}-0030-1256265$

Endoscopy 2011; 43: E160-E161

(c) Georg Thieme Verlag KG Stuttgart · New York . ISSN 0013-726X

\section{Corresponding author}

\section{K. Mönkemüller, MD, PhD, FASGE}

Division of Gastroenterology,

Hepatology and Infectious Diseases

Marienhospital Bottrop

Josef-Albers-Straße 70

46242 Bottrop

Germany

Fax: +49-2041-10161019

moenkemueller@yahoo.com 